\title{
ANALISIS KEPUASAN PELANGGAN DE LAUNDRY DENGAN MENGGUNAKAN METODE CUSTOMER SATISFACTION INDEX DAN SERVICE QUALITY
}

\author{
Aula Putri Anindya, Iva Mindhayani* \\ Program Studi Teknik Industri, Fakultas Sains dan Teknologi, Universitas Widya Mataram \\ Email: aulaputrianindya@gmail.com; ivamindhayani@gmail.com
}

Artikel masuk : 27-10-2021

\author{
Artikel direvisi : 09-11-2021 \\ *Penulis Korespondensi
}

Artikel diterima : 08-12-2021

\begin{abstract}
Abstrak -- Mutu pelayanan jasa yang baik menunjukkan produktivitas serta kemampuan menghasilkan kepuasan pelanggan. Penelitian ini menganalisis tingkat kepuasan pelanggan terhadap mutu pelayanan yang diberikan oleh De Laundry dan atribut prioritas perbaikan. Penelitian ini menggunakan kuesioner sebagai alat mengumpulkan data dengan 70 responden dan 27 butir pertanyaan. Metode pengolahan data menggunakan Customer Satisfaction Index dan Service Quality. Hasil penelitian menunjukkan tingkat kepuasan pelanggan De Laundry dengan menggunakan metode Customer Satisfaction Index sebesar $80 \%$ yang menunjukkan bahwa pelanggan merasa puas dengan layanan yang diberikan. Hasil metode Service Quality diketahui bahwa atribut dimensi Assurance berpengaruh terhadap kepuasan pelanggan dengan nilai kualitas pelayanan (Q) sebesar 1,0, serta diperoleh melalui hasil diagram kartesius bahwa atribut pelayanan yang perlu ditingkatkan atau menjadi prioritas utama dalam perbaikan guna meningkatkan kualitas pelayanan ialah atribut yang berada di Kuadran $A$.
\end{abstract}

Kata kunci: Customer Satisfaction Index; Kualitas Pelayanan; Service Quality

Abstract -- Good service quality shows productivity and the ability to produce customer satisfaction. This study analyzes the level of customer satisfaction with the quality of service provided by De Laundry and the priority attributes of improvement. This study uses a questionnaire to collect data with 70 respondents and 27 questions. The data processing method uses the Customer Satisfaction Index and Service Quality. The results showed that the level of customer satisfaction of De Laundry using the Customer Satisfaction Index method was $80 \%$ which showed that customers were satisfied with the services provided. The results of the Service Quality method are known that the Assurance dimension attribute affects customer satisfaction with a service quality value $(Q)$ of 1.0. It is obtained through the results of the Cartesian diagram that the service attributes that need to be improved or become a top priority in improvement to improve service quality are attributes in Quadrant $A$.

Keywords: Customer Satisfaction Index; Service Quality; Service Quality

\section{PENDAHULUAN}

Masa pandemi seperti saat ini, roda perekonomian mengalami penurunan yang sangat drastis. Hal ini berdasarkan Laporan Perekonomian Indonesia 2020 yang diterbitkan oleh Badan Pusat Statistik (BPS) bahwa tingkat pertumbuhan ekonomi Indonesia pada Kuartal I tahun 2020 sebesar 2,97 persen (Badan Pusat Statistik, 2020). Padahal Bank Indonesia tahun 2020 memperkirakan pertumbuhan ekonomi bisa mencapai 4,2 $-4,6$ persen.
Kebijakan pemerintah tentang pembatasan ruang gerak masyarakat membuat beberapa perusahaan menerapkan kebijakan baru, tidak sedikit perusahaan memilih untuk mengurangi karyawan agar proses produksi tetap berlangsung. Pengurangan karyawan ini merupakan salah satu penerapan protokol kesehatan yang bertujuan untuk memutus penyebaran virus covid - 19 dan menjaga kesehatan karyawan di masa pandemi. Banyak juga perusahaan yang gulung tikar karena omsetnya turun. Hal ini menyebab- 
kan meningkatnya jumlah pengangguran. Sulitnya perekonomian dan sedikitnya lapangan kerja dimasa pandemi menuntut masyarakat untuk menciptakan lapangan kerja sendiri. Masyarakat berlomba-lomba menciptakan lapangan pekerjaannya sendiri dengan mendirikan Usaha Kecil dan Menengah (UKM) diberbagai bidang, salah satunya bidang jasa laundry.

Laundry merupakan Usaha Kecil dan Menengah (UKM) yang berperan penting membantu perekonomian Indonesia, dengan menyediakan lapangan pekerjaan dan menghasilkan luaran yang bermanfaat bagi masyarakat, salah satunya adalah De Laundry. De Laundry merupakan salah satu penyedia jasa cuci dan setrika pakaian yang ada di Kediri Jawa Timur. Laundry ini berdiri sejak tahun 2015, bertempat di Jalan Mataram no. 74 Kecamatan Ngasem Kabupaten Kediri. Permasalahan yang dihadapi oleh De laundry adalah terkait pelayanan kepada pelanggan. Pelayanan kepada pelanggan merupakan luaran dari perusahaan yang bergerak dibidang jasa. Salah satu cara agar bisa bertahan di dunia persaingan bisnis ini ialah peningkatan kualitas sebagai upaya memenuhi keinginan pelanggan. salah satu kunci keberhasilan dalam persaingan bisnis adalah mutu pelayanan yang tinggi. Mutu pelayanan yang bagus menunjukkan produktivitas dan kemampuan menghasilkan kepuasan pelanggan yang merupakan tingkat perasaan atas kinerja yang dirasakan dibandingkan dengan harapan yang dimilikinya (Hidayati \& Prasetyo, 2015). Perusahaan dapat dibilang sukses apabila memiliki kepekaan terhadap keinginan pelanggan sehingga pelanggan akan merasa puas, nyaman, dan loyal terhadap perusahaan tersebut.

Kepuasan pelanggan berkaitan dengan mutu pelayanan suatu perusahaan. Peningkatan jumlah konsumen sebaiknya diikuti dengan peningkatan pelayanan yang dapat mendorong hubungan yang kuat antara konsumen dengan perusahaan. Hubungan tersebut dalam jangka panjang akan berdampak pada peningkatan kepuasan pelanggan dan meminimalkan ketidaknyamanan konsumen.

Kualitas barang atau produk mempunyai pengaruh terhadap kepuasan konsumen. Mutu yang baik menjadi salah satu prioritas perusahaan dalam menciptakan keunggulan bersaing. Kegagalan meningkatkan kualitas pelayanan akan membuat perusahaan berada dalam masalah yang kompleks. Konsumen yang merasa tidak puas akan menceritakan pengalamannya kepada calon konsumen ataupun konsumen yang lain sehingga berdampak pada kinerja perusahaan. Perencanaan, peng- organisasian, implementasi dan pengendalian manajemen kualitas barang atau produk wajib dilakukan untuk meningkatkan kepercayaan konsumen terhadap kualitas yang diterima dan akan berdampak positif pada kesetiaan pelanggan terhadap perusahaan. Beberapa metode yang digunakan untuk mengukur kepuasan pelanggan adalah metode customer satisfaction index dan service quality (servqual). Metode customer satisfaction index merupakan instrumen pengukuran untuk kepuasan pelanggan terhadap pelayanan yang sudah diterima yang berfokus pada pengaturan fisik (Hsu, 2008). Sedangkan metode service quality merupakan model pengukuran kualitas layanan dengan cara melakukan identifikasi gap antara harapan pelanggan atas pelayanan yang akan diberikan dengan pelayanan nyata yang diberikan.

Tingkat pelayanan yang baik akan memberikan kepuasan kepada konsumen seperti pelanggan sangat puas terhadap pelayanan yang diberikan ABC Laundry (Hadining, 2020), dimana tingkat kepuasan pelanggan sampai $91 \%$. Pemanfaatan teknologi juga mempunyai dampak terhadap peningkatan kualitas pelayanan kepada konsumen (Indra \& Siagian, 2021). Penelitian terkait analisis kepuasan pelanggan penting dilakukan guna mengetahui sejauh mana pelanggan merasa puas dengan servis yang diberikan oleh suatu organisasi atau perusahaan tersebut. Hal ini tentunya menjadi acuan dasar bagi perusahaan untuk lebih meningkatkan mutu pelayanan sehingga harapannya pelanggan benar-benar puas dan loyal terhadap perusahaan tersebut.

De Laundry selama ini telah berusaha untuk memberikan pelayanan yang terbaik. Namun demikian, perlu dilakukan analisa kepuasan pelanggan sehingga dapat mengetahui dengan pasti ada tidaknya pelanggan yang kurang puas dengan pelayanan yang diberikan oleh De laundry. Selama ini De Laundry belum pernah melakukan pengukuran kualitas pelayanan. Dengan dilakukannya pengukuran kualitas pelayanan dapat sebagai pertimbangan untuk mengembangkan bisnis jasa laundry dan melakukan perbaikan-perbaikan terkait kualitas pelayanan yang diberikan.

\section{METODE PENELITIAN}

Penelitian ini menggunakan kuesioner sebagai alat mengumpulkan data, yang mana respondennya merupakan pelanggan maupun konsumen dari De Laundry. Kuesioner yang dipakai menggunakan skala likert dimana memiliki bobot nilai berbeda setiap pilihannya (Sugiyono, 2018).

Tahap pertama yang dilakukan ialah 
menentukan jumlah ukuran responden dengan menggunakan perhitungan berikut:

$n=\frac{z^{2} \cdot p \cdot q}{e^{2}}$

dimana, $\mathrm{n}$ : ukuran sampel, $\mathrm{Z}$ : tingkat kepercayaan $(90 \%=1,645)$, e: Sampling error $(10 \%=0,1), p:$ proporsi dalam populasi and $\mathrm{q}$ : persentase kuesioner cacat $(q=1-p)$.

Apabila jumlah populasi belum diketahui maka nilai $p=0,5$. sehingga hasil perhitungan uji kecukupan data didapatkan bahwa jumlah sampel yang diambil dan dapat mewakili populasi adalah sebanyak 68 sampel. Pengambilan sampel ini dengan menyebar 70 kuesioner dengan 27 pernyataan, yang mana responden pengisi kuesioner merupakan konsumen ataupun pelanggan De Laundry yang sudah menggunakan jasa pencucian.
Kualitas jasa mempunyai lima dimensi yang menjadi dasar pengukuran tingkat kepuasan konsumen (Zeithaml et al., 1988). Kelima dimensi itu adalah tangible (fasilitas fisik, peralatan dan penampilan pribadi); reliability (kemampuan untuk melakukan layanan yang dijanjikan untuk dapat dipercaya dan akurat); responsiveness (kesediaan membantu dan memberikan pelayanan yang cepat); assurance (pengetahuan dan kesopanan karyawan, keramahan dan memiliki sifat dapat dipercaya sehingga membuat pelanggan yakin dan merasa terhindar dari risiko) dan empathy (perhatian personal yang diberikan perusahaan kepada pelanggan, kemampuan berkomunikasi karyawan dan kemudahan menghubungi perusahaan). Hasil identifikasi berdasarkan lima dimensi tersebut dapat dilihat pada Tabel 1 .

Tabel 1. Dimensi dan Atribut Pelayanan

\begin{tabular}{|c|c|c|}
\hline Dimensi & Variabel & Jumlah \\
\hline Tangibles & $\begin{array}{l}\text { - Tidak ada noda di cucian setelah dicuci } \\
\text { - Cucian tidak bau apek } \\
\text { - Cucian tidak rusak } \\
\text { - Warna cucian tidak pudar } \\
\text { - Cucian tidak kelunturan warna } \\
\text { - Hasil setrika rapih } \\
\text { - Cucian bersih dibungkus dengan rapi } \\
\text { - Peralatan De laundry yang dimiliki lengkap } \\
\text { - Penampilan outlet De Laundry rapi dan menarik }\end{array}$ & 9 item \\
\hline Reliability & $\begin{array}{l}\text { - Pengerjaan cucian selalu tepat waktu } \\
\text { - Cucian tidak tertukar } \\
\text { - Cucian tidak hilang } \\
\text { - Promosi dalam bentuk potongan harga } \\
\text { - Promosi pemberian cucian gratis } \\
\text { - Layanan Antar - Jemput } \\
\text { - Pembayaran fleksibel, }\end{array}$ & 7 item \\
\hline Responsiveness & $\begin{array}{l}\text { - Karyawan cepat dalam merespon permintaan } \\
\text { pelanggan } \\
\text { - Karyawan dapat menangani setiap keluhan dengan } \\
\text { cepat dan tepat } \\
\text { - Karyawan selalu menawarkan bantuan kepada setiap } \\
\text { pelanggan }\end{array}$ & 3 item \\
\hline Assurance & $\begin{array}{l}\text { - Informasi yang diberikan para karyawan selalu tepat } \\
\text { - Pemberianya garansi bila cucian tertukar/ hilang } \\
\text { - Pemberian garansi bila cucian rusak } \\
\text { - Pengetahuan karyawan luas dan tepat } \\
\text { - Karyawan De Laundry terampil dalam bekerja }\end{array}$ & 5 item \\
\hline Empathy & $\begin{array}{l}\text { - Karyawan selalu membantu dengan tulus } \\
\text { - Karyawan selalu berkomunikasi dengan baik, sopan, } \\
\text { dan ramah } \\
\text { - Karyawan selalu tau keinginan pelanggan }\end{array}$ & 3 item \\
\hline
\end{tabular}


Customer Satisfaction Index merupakan alat yang digunakan untuk mengetahui tingkat kepuasan secara menyeluruh dari pengguna jasa berdasarkan hasil dari tingkat harapan dan kinerja masing-masing atribut (Umam \& Hariastuti, 2018). Model tersebut menghubungkan kepuasan pelanggan dengan faktor-faktor penentunya dan, pada gilirannya berkonsekuensi pada loyalitas pelanggan (Kristensen et al., 2000). Tabel 2 yang merupakan interpretasi nilai $\mathrm{CSI}$, dimana $\mathrm{X}$ adalah angka indeks kepuasan.

Tabel 2. Customer Satisfaction Index Interpretation

\begin{tabular}{cc}
\hline Angka Indeks & Kriteria CSI \\
\hline $0,00 \leq X \leq 0,34$ & Tidak Puas \\
$0,35 \leq X \leq 0,50$ & Kurang Puas \\
$0,51 \leq X \leq 0,65$ & Cukup Puas \\
$0,66 \leq X \leq 0,80$ & Puas \\
$0,08<X$ & Sangat Puas \\
\hline
\end{tabular}

Tabel 2 digunakan untuk menentukan hasil dari perhitungan rumus $\mathrm{CSI}$.

$C S I=\frac{T}{5 \times Y} \times 100 \%$

Nilai $\mathrm{T}$ didapat dari menjumlahkan seluruh nilai pada kolom skor (S). Kolom skor (S) diperoleh dari hasil kali kolom kepentingan (I) dengan kolom kepuasan (P). Nilai $Y$ merupakan hasil penjumlahan nilai rata - rata dari Kepentingan (I). Nilai 5 (pada $5 \times$ Y) adalah nilai maksimum yang digunakan pada skala pengukuran. Perhitungan CSI secara keseluruhan menurut Bhoe dapat dilihat pada Tabel 3 (Widodo \& Sutopo, 2018).

Tabel 3. Customer Satisfaction Index

\begin{tabular}{|c|c|c|c|}
\hline $\begin{array}{c}\text { Atribut / } \\
\text { Indikator }\end{array}$ & $\begin{array}{c}\text { Kepentingan } \\
\text { (I) } \\
\text { Skala } 1-5\end{array}$ & $\begin{array}{c}\text { Kepuasan } \\
\text { (P) } \\
\text { Skala } 1-5\end{array}$ & $\begin{array}{l}\text { Skor (S) } \\
\text { S = I } \times \mathbf{P}\end{array}$ \\
\hline$\ldots \ldots$. & & & \\
\hline $\begin{array}{l}\text { Skor } \\
\text { Total }\end{array}$ & Total $(\mathrm{I})=\mathrm{Y}$ & & $\begin{array}{c}\text { Total (S) } \\
=\mathrm{T}\end{array}$ \\
\hline
\end{tabular}

Pengukuran kualitas pelayanan dengan menggunakan metode Service Quality dilakukan dengan cara melihat perbandingan tingkat kinerja dan tingkat harapan. Nilai kesenjangan yang terjadi merupakan selisih hasil tingkat harapan dan tingkat kinerja yang terjadi dalam suatu pelayanan (Ulkhaq \& Barus, 2017). Nilai gap merupakan hasil dari pengurangan nilai persepsi/kepuasan terhadap layanan dengan nilai harapan/kepentingan yang diinginkan konsumen. Langkah-langkah dalam mengguna- kan metode service quality (Yuniar et al., 2014) adalah:

1. Tentukan nilai persepsi rata-rata pada masing-masing variabel.

$$
\vec{p}=\frac{\sum_{i=1}^{n} p_{i}}{n}
$$

Dimana $\mathrm{P}_{\mathrm{i}}$ : nilai persepsi yang diberikan pelanggan untuk pertanyaan ke-I dan $\mathrm{n}$ : jumlah responden

2. Tentukan rata-rata nilai harapan pada masing-masing variabel

$\vec{E}=\frac{\sum_{i=1}^{n} E_{i}}{n}$

Dimana, $E_{\mathrm{i}}$ : nilai harapan yang diberikan Pelanggan untuk pertanyaan ke-I dan $n$ adalah jumlah responden

3. Tentukan nilai servqual (gap) pada masingmasing variabel

$G A P=$ Persepsi - Harapan

Persepsi: nilai persepsi pelanggan atas pelayanan yang dirasakan secara nyata dan Harapan = nilai ekspektasi/harapan pelanggan terhadap pelayanan yang didapat.

Berdasarkan rumus 5 yang menyatakan bahwa kualitas pelayanan merupakan selisih atau perbedaan dari persepsi dan harapan sehingga hipotesis yang dikemukakan oleh Handoko (2013) terdapat hubungan positif antara gap kualitas jasa, dengan kepuasan pelanggan.

\section{HASIL DAN PEMBAHASAN}

Hasil tabulasi data responden (Tabel 4) diketahui bahwa nilai rata-rata untuk dimensi tangible, responsiveness, assurance dan empathy adalah $>4$. Sedangkan dimensi reliability adalah 3,94. Sehingga rata-rata keseluruhan variabel kepuasan terhadap persepsi pelanggan adalah 4,08 (> 4) yang berarti pelanggan merasa puas atas persepsi.

Tabulasi data responden (Tabel 5) terkait kepuasan terhadap harapan pelanggan memperlihatkan bahwa terdapat dimensi yang memiliki nilai rata-rata $>4$ yaitu tangible, responsive dan empathy. Sedangkan 2 dimensi memiliki nilai $<4$ yaitu reliability dan assurance. Rata-rata keseluruhan variabel kepuasan terhadap pelanggan memiliki nilai $>4$ yang berarti pelanggan merasa puas terhadap harapan.

Tabel 4. Data Kepuasan Terhadap Persepsi

\begin{tabular}{ccc}
\hline No & Dimensi & Mean \\
\hline 1 & Tangible & 4,02 \\
2 & Reliability & 3,94 \\
3 & Responsiveness & 4,17 \\
4 & Assurance & 4,18 \\
5 & Empathy & 4,10 \\
Variabel Kepuasan terhadap & 4,08 \\
Persepsi Pelanggan & \\
\hline
\end{tabular}


Uji validitas merupakan alat pengukuran kevalidan data data suatu kuesioner. Hal pertama yang dilakukan dengan cara mencari rtabel, dalam penelitian ini memiliki 70 data dengan tingkat signifikansi $5 \%$, maka nilai $r_{\text {tabel }}$

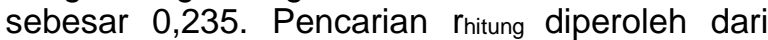
pengolahan data dengan menggunakan software SPSS 24 dengan $r_{\text {hitung }}$ terkecil dari hasil output SPSS adalah 0,288 sedangkan $r_{\text {hitung }}$ terbesar adalah 0,936. Nilai $r_{\text {hitung }}>r_{\text {tabel, }}$ maka item kuesioner dinyatakan valid.

Tabel 5. Data Kepuasan Terhadap Harapan

\begin{tabular}{ccc}
\hline No & Dimensi & Mean \\
\hline 1 & Tangible & 4,21 \\
2 & Reliability & 3,95 \\
3 & Responsiveness & 4,10 \\
4 & Assurance & 3,99 \\
5 & Empathy & 4,15 \\
Variabel Kepuasan terhadap & 4,08 \\
Harapan Pelanggan & \\
\hline
\end{tabular}

Uji Reliabilitas digunakan untuk mengetahui seberapa reliabel dan konsisten sarana yang diukur dengan melihat nilai Cronbach Alpha. Reliabilitas hasil kuesioner menunjukkan hasil yang relatif sama atau tetap jika digunakan pada objek lain (Arikunto, 1983). Perhitungan uji reliabilitas pada penelitian ini dibantu menggunakan software SPSS 24, dengan membandingkan

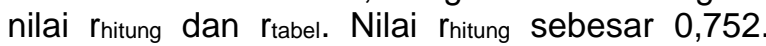
Apabila rhitung $>0,6$ berarti data tersebut reliabel.

\section{Customer Satisfaction Index}

Perhitungan indeks kepuasan konsumen dapat diketahui dengan menggunakan nilai rerata tingkat harapan dan persepsi dari masingmasing atribut. Berikut tabel 6 merupakan hasil pengolahan data Customer Satisfaction Index menggunakan Ms. Excel.

Berdasarkan hasil pengolahan data yang ditampilkan pada Tabel 6 dapat dilihat nilai kepentingan dan kepuasan. Skor (S) didapat dengan mengalikan kepentingan (I) dan kepuasan $(P)$. Lalu dijumlahkan keseluruhan nilai S sehingga Hasil perhitungan didapat nilai total $S$ adalah 438,372 . Kemudian nilai $S$ digunakan untuk menghitung nilai Customer Satisfaction Index dengan menggunakan rumus 2 .

$$
\begin{aligned}
& C S I=\frac{T}{5 \times Y} \times 100 \% \\
& C S I=\frac{438,372}{5 \times 108,943} \times 100 \%=80 \%
\end{aligned}
$$

Dari hasil perhitungan diketahui bahwa nilai Customer Satisfaction Index sebesar $80 \%$. Dengan demikian tingkat kepuasan pelanggan
De Laundry dinyatakan cukup, berdasarkan angka indeks kepuasan. Senada dengan hasil penelitian Gumilar (2021) mengemukakan bahwa pelanggan merasa puas dengan pelayanan di laundry terlihat dari hasil perhitungan Customer Services Index sebesar $80,64 \%$.

\begin{tabular}{|c|c|c|c|}
\hline $\begin{array}{c}\text { No. } \\
\text { Atribut }\end{array}$ & $\begin{array}{c}\text { I } \\
\text { (Kepentingan) }\end{array}$ & $\begin{array}{c}\mathbf{P} \\
\text { (Kepuasan) }\end{array}$ & $S=I \times P$ \\
\hline 1. & 4,300 & 4,171 & 17,935 \\
\hline 2. & 4,314 & 4,186 & 18,058 \\
\hline 3. & 4,300 & 3,771 & 16,215 \\
\hline 4. & 4,014 & 4,014 & 16,112 \\
\hline 5. & 3,871 & 3,857 & 14,930 \\
\hline 6. & 4,314 & 4,157 & 17,933 \\
\hline 7. & 4,243 & 3,771 & 16,000 \\
\hline 8. & 4,286 & 4,157 & 17,817 \\
\hline 9. & 4,300 & 4,157 & 17,875 \\
\hline 10. & 4,286 & 4,171 & 17,877 \\
\hline 11. & 3,843 & 3,957 & 15,207 \\
\hline 12. & 3,714 & 3,671 & 13,634 \\
\hline 13. & 3,943 & 3,957 & 15,602 \\
\hline 14. & 3,843 & 3,857 & 14,822 \\
\hline 15. & 4,300 & 4,157 & 17,875 \\
\hline 16. & 3,714 & 3,771 & 14,005 \\
\hline 17. & 4,286 & 4,157 & 17,817 \\
\hline 18. & 4,286 & 4,157 & 17,817 \\
\hline 19. & 3,714 & 4,186 & 15,547 \\
\hline 20. & 3,786 & 4,186 & 15,848 \\
\hline 21. & 3,843 & 4,171 & 16,029 \\
\hline 22. & 4,300 & 4,286 & 18,430 \\
\hline 23. & 3,714 & 4,114 & 15,279 \\
\hline 24. & 4,286 & 4,157 & 17,817 \\
\hline 25. & 3,043 & 2,700 & 8,216 \\
\hline 26. & 3,843 & 4,157 & 15,975 \\
\hline 27. & 4,257 & 4,157 & 17,696 \\
\hline Total & 108,943 & & 438,372 \\
\hline
\end{tabular}

Tabel 6. Hasil Perhitungan CSI

\section{Service Quality}

Nilai service quality didapatkan dengan menghitung gap atau kesenjangan tiap atribut, nilai tersebut hasil dari pengurangan nilai persepsi/kepuasan terhadap layanan dengan nilai harapan/kepentingan yang diinginkan konsumen. Hasil perhitungan gap dengan nilai () berarti tingkat kinerja pelayanan yang diterima pelanggan tidak sesuai dengan harapan yang diinginkannya. Apabila hasil perhitungan gap memiliki nilai (+) maka persepsi pelanggan lebih besar atau terpenuhi dengan harapan yang diinginkan. Setelah memperoleh nilai tersebut maka diberikan peringkat untuk mengetahui nilai gap terbesar dan terkecil dari seluruh atribut. Perhitungan nilai GAP menggunakan rumus 5 untuk mengetahui atribut atau parameter yang 
mempunyai hasil pelayanan yang baik dan hasil pelayanan yang kurang baik.

Tabel 7. Nilai Gap Keseluruhan Dimensi Atribut

\begin{tabular}{ccccr}
\hline No. & Harapan & Persepsi & Gap & Ranking \\
\hline 1. & 4,300 & 4,171 & $-0,129$ & 17 \\
2. & 4,314 & 4,186 & $-0,128$ & 16 \\
3. & 4,300 & 3,771 & $-0,529$ & 27 \\
4. & 4,014 & 4,014 & 0 & 10 \\
5. & 3,871 & 3,857 & $-0,014$ & 11 \\
6. & 4,314 & 4,157 & $-0,157$ & 24 \\
7. & 4,243 & 3,771 & $-0,472$ & 26 \\
8. & 4,286 & 4,157 & $-0,129$ & 17 \\
9. & 4,300 & 4,157 & $-0,143$ & 22 \\
10. & 4,286 & 4,171 & $-0,115$ & 15 \\
11. & 3,843 & 3,957 & 0,114 & 6 \\
12. & 3,714 & 3,671 & $-0,043$ & 13 \\
13. & 3,943 & 3,957 & 0,014 & 9 \\
14. & 3,843 & 3,857 & 0,014 & 8 \\
15. & 4,300 & 4,157 & $-0,143$ & 22 \\
16. & 3,714 & 3,771 & 0,057 & 7 \\
17. & 4,286 & 4,157 & $-0,129$ & 17 \\
18. & 4,286 & 4,157 & $-0,129$ & 17 \\
19. & 3,714 & 4,186 & 0,472 & 1 \\
20. & 3,786 & 4,186 & 0,4 & 2 \\
21. & 3,843 & 4,171 & 0,328 & 4 \\
22. & 4,300 & 4,286 & $-0,014$ & 12 \\
23. & 3,714 & 4,114 & 0,4 & 2 \\
24. & 4,286 & 4,157 & $-0,129$ & 17 \\
25. & 3,043 & 2,700 & $-0,343$ & 25 \\
26. & 3,843 & 4,157 & 0,314 & 5 \\
27. & 4,257 & 4,157 & $-0,1$ & 14 \\
\hline & & & &
\end{tabular}

Hasil perhitungan nilai GAP yang ditunjukkan pada Tabel 7 terlihat bahwa yang bernilai positif terdapat 10 item yaitu atribut no 4 , $11,13,14,16,19,20,21,23$, 26, dan yang bernilai negatif terdapat 17 item yaitu atribut no 1 , 2, 3, 5,6,7,8,9,10,12, 15, 17, 18, 22, 24, 25 dan 27. Setelah mendapatkan nilai gap maka hal selanjutnya menganalisis kualitas pelayanan menggunakan rumus sebagai berikut (Besterfield, 2011):

Kualitas Layanan $(Q)=\frac{\operatorname{Persepsi}(P)}{\operatorname{Harapan}(I)}$

Dari hasil perhitungan menggunakan rumus 6 maka diketahui seberapa besar kecilnya kualitas layanan di masing - masing dimensi. Nilai (Q) yang terbesar menunjukkan kualitas pelayanan yang baik atau dapat memuaskan keinginan pelanggan, sedangkan yang terkecil menunjukkan kualitas layanan kurang memuaskan. Nilai $(Q)=1$ mempunyai arti bahwa tingkat kualitas pelayanan sudah dikategorikan baik (Zeithaml et al., 1988).
Berdasarkan Tabel 8 diketahui terdapat 3 dimensi yang bernilai positif dimulai yang paling besar adalah nilai GAP terbesar adalah assurance sebesar 0,197, lalu responsiveness sebesar 0,071 dan empathy sebesar 0,043. Sedangkan 2 dimensi memiliki nilai negatif adalah reliability sebesar $-0,015$ dan tangible sebesar -0,189. Untuk kualitas pelayanan dimensi responsiveness dan assurance memiliki nilai $Q=1$ sedangkan dimensi reliability memiliki nilai $Q=0,99$, empathy memiliki nilai $Q=0,98$ tangible memiliki nilai $Q=0,95$. Hasil nilai ratarata kualitas layanan memiliki nilai $=1$, hal tersebut menandakan bahwa kualitas layanan De Laundry dapat dikatakan cukup baik. Senada dengan Sholikah \& Iriananda (2017) dalam penelitiannya menyatakan bahwa hasil perhitungan gap per kriteria dan per dimensi diperoleh nilai tinggi terdapat pada dimensi tangible, sehingga dijadikan prioritas utama dalam meningkatkan kualitas pelayanan jasa travel.

Tabel 8. Perhitungan Kualitas Layanan

\begin{tabular}{|c|c|c|c|c|}
\hline Dimensi & $\begin{array}{l}\text { Harapan } \\
\text { (I) }\end{array}$ & $\begin{array}{l}\text { Persepsi } \\
\text { (P) }\end{array}$ & Gap & $\begin{array}{l}Q= \\
P / I\end{array}$ \\
\hline Tangibles & 4,216 & 4,027 & $\begin{array}{c}- \\
0,189\end{array}$ & 0,95 \\
\hline Reliability & 3,949 & 3,934 & $\begin{array}{c}- \\
0,015\end{array}$ & 0,99 \\
\hline Responsiveness & 4,095 & 4,167 & 0,071 & 1,0 \\
\hline Assurance & 3,986 & 4,183 & 0,197 & 1,0 \\
\hline Empathy & 3,71 & 3,671 & $0, \overline{043}$ & 0,98 \\
\hline Rata-rata & 3,99 & 3,996 & 3,996 & 1 \\
\hline
\end{tabular}

Nilai kualitas layanan $(Q)$ yang ditunjukkan pada Tabel 8 yang menggambarkan nilai keseluruhan tiap-tiap dimensi Selanjutnya setelah mengetahui nilai gap masing-masing dimensi dan secara keseluruhan. Langkah analisis persepsi terhadap pelayanan dan harapan dari pelanggan untuk mengetahui posisi masing masing atribut berdasarkan tingkat kinerja dan tingkat harapan pelanggan. Analisis ini berupa diagram kartesius. Dengan diagram kartesius, tiap-tiap butir atribut yang menjadi prioritas utama perbaikan dapat diketahui. Pada diagram kartesius menunjukkan letak kuadran masing masing dimensi atribut atau keseluruhan, yang mana tingkat persepsi adalah $\mathrm{Y}$ dan tingkat harapan adalah X. Diagram Kartesius dibagi menjadi empat kuadran, kuadran ini mempresentasikan pengaruh kualitas pelayanan. Kuadran A (prioritas utama), kuadran B (prioritas kedua), kuadran $\mathrm{C}$ (prioritas rendah) dan kuadran $\mathrm{D}$ (prioritas sangat rendah). 
Hasil diagram kartesius dapat diketahui bahwa atribut pelayanan yang perlu ditingkatkan atau menjadi prioritas utama dalam perbaikan guna meningkatkan kualitas pelayanan ialah atribut yang berada di Kuadran A (Gambar 1), sebagai berikut:

1. Warna cucian tidak pudar (T4)

2. Karyawan De Laundry selalu menawarkan bantuan kepada setiap pelanggan (Rs3)

3. Informasi yang diberikan para karyawan selalu tepat $(A 1)$

4. Pemberian garansi bila cucian tertukar/ hilang (A2)

5. Pengetahuan karyawan luas dan tepat (A4)

6. Karyawan De Laundry selalu berkomunikasi dengan baik, sopan, dan ramah (E2)

Kuadran A menjadi prioritas penting yang diprioritaskan perusahaan. Responden menganggap bahwa atribut-atribut ini sangat penting tetapi kinerjanya rendah (Hudson et al., 2004)

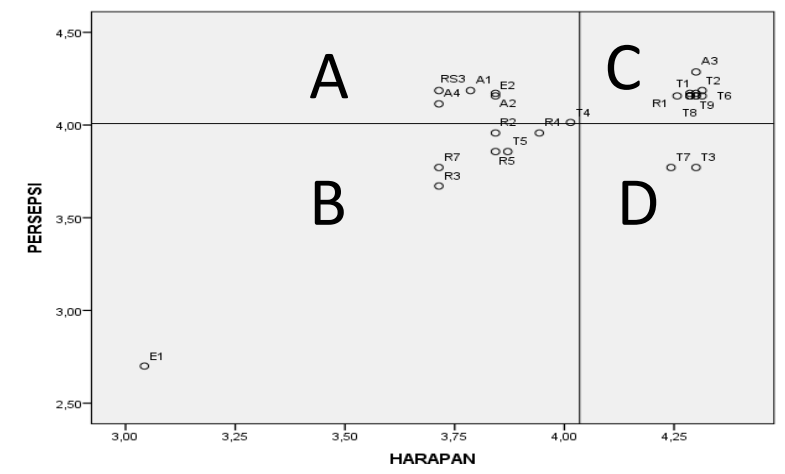

Gambar 1. Diagram Kartesius

Perbaikan yang perlu dilakukan oleh pihak manajemen De Laundry yaitu selalu berusaha meningkatkan kualitas pelayanan yang mencakup lima atribut dimensi yaitu tangibles, reliability, responsiveness, assurance, dan empathy agar kepuasan konsumen atau pelanggan semakin meningkat. Hal tersebut dapat dilakukan dengan cara menambah jumlah karyawan dan meningkatkan konsistensi kinerja karyawan supaya pelanggan loyal atau setia pada De Laundry. Peningkatan konsistensi kinerja data dilakukan dengan memberikan training pada karyawan De Laundry supaya mampu berkomunikasi dengan baik serta menambah pengetahuan terkait bagaimana cara menangani pelanggan dengan baik, training cara cara mencuci dan menyetrika pakaian dengan baik dan benar. Selain itu pemilik usaha dapat membuat SOP yang tepat dan realistis.

Senada dengan hasil penelitian yang dilakukan oleh Hadining (2020) bahwa terdapat atribut yang perlu dilakukan perbaikan yaitu terkait kemampuan dan pengetahuan karyawan mengenai cara menangani keluhan pelanggan dengan baik dan benar serta bertanggung jawab terhadap cucian pelanggan supaya terhindar dari tertukar atau hilang. Khoirurrohman et al. (2016) dalam penelitiannya juga menyatakan bahwa keterampilan karyawan searah dengan kepuasan pelanggan.

\section{KESIMPULAN}

Tingkat kepuasan konsumen maupun pelanggan De Laundry dengan menggunakan metode Customer Satisfaction Index sebesar $80 \%$. Berdasarkan tabel indeks kepuasan pelanggan persentase tersebut menunjukkan bahwa pelanggan merasa puas dengan layanan atau kinerja yang diberikan. Hal ini harus dipertahankan dan perlu ditingkatkan oleh pihak manajemen agar dapat mencapai persentase $100 \%$. Hasil pengolahan data menggunakan metode service quality dapat diketahui bahwa atribut dimensi tangible pada variabel cucian tidak rusak, hasil setrika rapi berpengaruh terhadap kepuasan pelanggan. Berdasarkan pengolahan data yang diperoleh melalui hasil diagram kartesius dapat diketahui bahwa atribut pelayanan yang perlu ditingkatkan atau menjadi prioritas utama dalam perbaikan guna meningkatkan kualitas pelayanan ialah atribut yang berada di Kuadran A. Penilaian kualitas layanan yang dilakukan diambil secara menyeluruh. Untuk itu, selanjutnya penilaian layanan kualitas dengan melihat penilaian per individu. Karena ada beberapa dimensi lain yang memerlukan perbaikan berdasarkan hasil dari pengukuran menggunakan metode servqual. Saran untuk penelitian lanjutan yaitu dengan melakukan pengukuran pada masing-masing GAP (GAP 1 - GAP 4).

\section{DAFTAR PUSTAKA}

Arikunto, S. (1983). Prosedur penelitian: suatu pendekatan praktik. PT. Bina Aksara, Jakarta.

https://books.google.co.id/books?id=6PKbA QAACAAJ

Badan Pusat Statistik. (2020). Ekonomi Indonesia triwulan I 2020 tumbuh 2, 97 persen. Jakarta (ID): Badan Pusat Statistik. https://www.bps.go.id/pressrelease/2020/05 /05/1736/ekonomi-indonesia-triwulan-i2020-tumbuh-2-97-persen.html

Besterfield, D. H. (2011). Total Quality Management. Pearson. https://books.google.co.id/books?id=n67M3 XJB91IC

Gumilar, R. (2021). Tingkat Kepuasan Pelayanan Pelanggan $\mathrm{Di}$ Laundry Menggunakan 
Customer Satisfaction Index. JITMI (Jurnal IImiah Teknik Dan Manajemen Industri), 3(2), 149-152.

http://www.openjournal.unpam.ac.id/index.p $\mathrm{hp} / \mathrm{JITM} /$ article/view/9528

Hadining, A. F. (2020). Analisis Kepuasan Pelanggan ABC Laundry Dengan Menggunakan Metode Service Quality, Importance Performance Analysis (IPA) dan Customer Satisfaction Index (CSI). J@Ti Undip: Jurnal Teknik Industri, 15(1), 1-10. https://doi.org/10.14710/jati.15.1.1-10

Handoko, H. (2013). Analisis pengaruh kualitas pelayanan (service quality) sistem informasi akademik terhadap kepuasan mahasiswa (studi kasus stmik amikom yogyakarta dan amikom cipta darma surakarta). Among Makarti, $\quad 4(2)$, 24-36. https://jurnal.stieama.ac.id/index.php/ama/a rticle/view/73

Hidayati, S. N., \& Prasetyo, A. P. (2015). Analisis Kualitas Pelayanan E-KTP Menggunakan Metode Customer Satisfaction Index, Metode Service Quality, dan Importance Performance Analysis. Jurnal Maksipreneur: Manajemen, Koperasi, Dan Entrepreneurship, 5(1), 117-133. http://dx.doi.org/10.30588/jmp.v5i1.149

Hsu, S.-H. (2008). Developing an index for online customer satisfaction: Adaptation of American Customer Satisfaction Index. Expert Systems with Applications, 34(4), 3033-3042.

https://doi.org/10.1016/j.eswa.2007.06.036

Hudson, S., Hudson, P., \& Miller, G. A. (2004). The Measurement of Service Quality in the Tour Operating Sector: A Methodological Comparison. Journal of Travel Research, 42(3), 305-312. https://doi.org/10.1177/0047287503258839

Indra, N., \& Siagian, A. O. (2021). Analisis Kualitas Pelayanan Kepuasan dan Pemanfaatan Teknologi Terhadap Pelanggan Go-Jek Pada Masa Covid-19. Jurnal Akrab Juara, 6(1), 194-212. http://akrabjuara.com/index.php/akrabjuara/ article/view/1384

Khoirurrohman, M. F., Hartono, B., \& Utami, H. D. (2016). Analisis kualitas pelayanan terhadap kepuasan konsumen dalam pembelian ayam goreng di "Ayam Goreng Roker" di Malang. Jurnal IImu-IImu Peternakan (Indonesian Journal of Animal Science), 25(2), 80-88. http://dx.doi.org/10.21776/ub.jiip.2015.025.0 2.10

Kristensen, K., Martensen, A., \& Gronholdt, L. (2000). Customer satisfaction measurement at Post Denmark: Results of application of the European Customer Satisfaction Index Methodology. Total Quality Management, 11(7), 1007-1015. https://doi.org/10.1080/0954412005013553 3

Sholikah, H., \& Iriananda, S. W. (2017). Analisis kepuasan pelanggan travel menggunakan metode fuzzy service quality. JOINTECS (Journal of Information Technology and Computer Science), 2(2), 53-58. https://doi.org/10.31328/jointecs.v2i2.468

Sugiyono, S. (2018). Metode Penelitian Kombinasi (Mix Methods). Bandung:

Alfabeta.

https://opac.perpusnas.go.id/DetailOpac.as $\mathrm{px}$ ?id=853411

Ulkhaq, M. M., \& Barus, M. P. B. (2017). Analisis Kepuasan Pelanggan dengan Menggunakan SERVQUAL: Studi Kasus Layanan IndiHome PT. Telekomunikasi Indonesia, Tbk, Regional 1 Sumatera. Jurnal Sistem Dan Manajemen Industri, 1(2), 61-67. https://doi.org/10.30656/jsmi.v1i2.365

Umam, R. K., \& Hariastuti, N. P. (2018). Analisa Kepuasan Pelanggan Dengan Menggunakan Metode Customer Satisfaction Index (CSI) Dan Importance Performance Analysis (IPA). Prosiding Seminar Nasional Sains Dan Teknologi Terapan, 339-344. https://ejurnal.itats.ac.id/sntekpan/article/vie w/366

Widodo, S. M., \& Sutopo, J. (2018). Metode Customer Satisfaction Index (CSI) untuk mengetahui pola kepuasan pelanggan pada e-commerce model business to customer. Jurnal Informatika Upgris, 4(1), 38-45. http://journal.upgris.ac.id/index.php/JIU/artic le/view/2224

Yuniar, S. S., Arijanto, S., \& Liansari, G. P. (2014). Usulan Perbaikan Kualitas Pelayanan Jasa Pengiriman Paket Berdasarkan Hasil Pengukuran Menggunakan Metode Service Quality (Servqual) Di PT. X. REKA INTEGRA, 2(2), 98-109.

https://ejurnal.itenas.ac.id/index.php/rekaint egra/article/view/413

Zeithaml, V. A., Berry, L. L., \& Parasuraman, A. (1988). SERVQUAL: a multiple-item scale for measuring consumer perceptions of service quality. Journal of Retailing, 64(1), 12-40.

https://www.researchgate.net/publication/22 5083802 